\title{
Johann Gaspar Spurzheim (1775-1832) and his contributions to our understanding of neuroanatomy
}

\author{
Felipe Hada Sanders ${ }^{1,2}$ - Christian Fisahn ${ }^{2,3}$. Joe Iwanaga ${ }^{2}$ - Rod. J. Oskouian ${ }^{3}$. \\ R. Shane Tubbs ${ }^{2,4}$
}

Received: 1 July 2016/Accepted: 5 July 2016/Published online: 30 July 2016

(C) Springer-Verlag Berlin Heidelberg 2016

"I do not want you to believe what I propose to you; I only want you to hear what I have to say; and then go into the world and see and judge for yourselves whether it be true."

J.G. Spurzheim

\section{Early life}

Johann Gaspar Spurzheim (portrait depicted in Fig. 1) was born on December 31, 1775 in the city of Longuich, then under the rule of Prussia, now Germany. There are reports of him being born 1776, and other reports with John as his first name $[1,2]$. He was the son of a farmer and was raised according to the Lutheran church. Spurzheim received a classical religious education at the College of Treves (now Trier). In

Felipe Hada Sanders

felipe.sanders@hc.fm.usp.br

1 Neurosurgery Division; Hospital das Clinicas, Faculdade de Medicina da Universidade de São Paulo, Sao Paulo, SP, Brazil

2 Seattle Science Foundation, Seattle, WA, USA

3 Swedish Neuroscience Institute, Swedish Medical Center, Seattle, WA, USA

4 Department of Anatomical Sciences, St. George's University, True Blue, Grenada
1797, due to war between Germany and France, he was forced to move to Austria, where he studied medicine at the University of Vienna [3]. During this time, he became a student and laboratory assistant of physician Franz Josef Gall. The two would later write books and publish together. Gall founded the new science devoted to attributing mental abilities to physical characteristics of the skull; together with Spurzheim, this new science "phrenology" (Greek $\varphi \rho \eta ์ v$

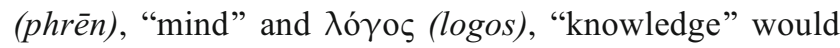
spread throughout Europe [4].

\section{Rise of a new "science"}

From 1807 to 1813, Spurzheim worked and lectured in Paris and found a growing number of followers for his and Gall's teachings on the brain and its relationships to skull shape and markings. This new "science" related the shape and size of the cranium to, for example, character and mental abilities $[5,6]$. In this regard, his lectures at the University of Paris were so popular that they "filled to overcrowding, not only his big lecture room, but all the staircases, stairs and corridors leading to it were filled with audience" [5]. In 1813, Spurzheim left his partnership with Gall and struck out on his own [6, 7]. Four years later, he was made Licentiate of The Royal College of Physicians and in 1821, received a Doctor of Medicine from the University of Paris. While in Paris, Spurzheim gave lectures on the anatomy, physiology, and pathology of the brain. He devoted himself to the practice of medicine. His wife was from Paris and used her remarkable artistic skills to help illustrate his books and presentations on phrenology and the brain, in general [8]. 


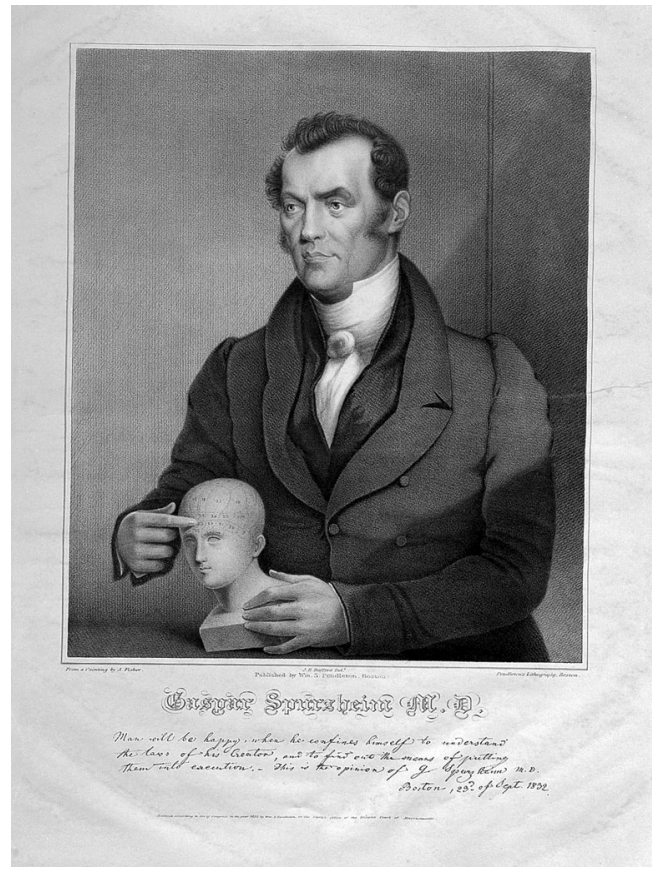

Fig. 1 Johann Caspar Spurzheim [18]

\section{Publications}

Spurzheim's publications regarding what is now known as phrenology included The Physiognomical System [9], Philosophical Principles of Phrenology, and Philosophical Catechism of the Natural Laws of Man. Spurzheim's Outlines of Phrenology [10] was published in Boston shortly before his death in 1832 . This book aimed to explain the theories regarding phrenology [11]. He also wrote on insanity [12] and education the latter with his Elementary Principles of Education [13].

However, Spurzheim's The Anatomy of the Brain [14], first translated into English in 1826, reviewed his and Gall's investigations of the brain and the nervous system and is his most lasting influence on our true knowledge of the anatomy of the brain and other parts of the nervous system. In this book, he made many detailed observations that helped our understanding of brain anatomy (see Figs. 2 and 3). For example, the corpus callosum and its connections were better described. The anterior commissure was also thoroughly dissected and described along with comparing it to the anterior commissure of other animals. Spurzheim described intricate connections between the brain and the olfactory tracts as well as he described the foramen of Monro as a cleft and disagreed that it was a foramen. Lastly, his techniques of brain dissection along with vivid depictions were a stepping stone for future researches of anatomy.

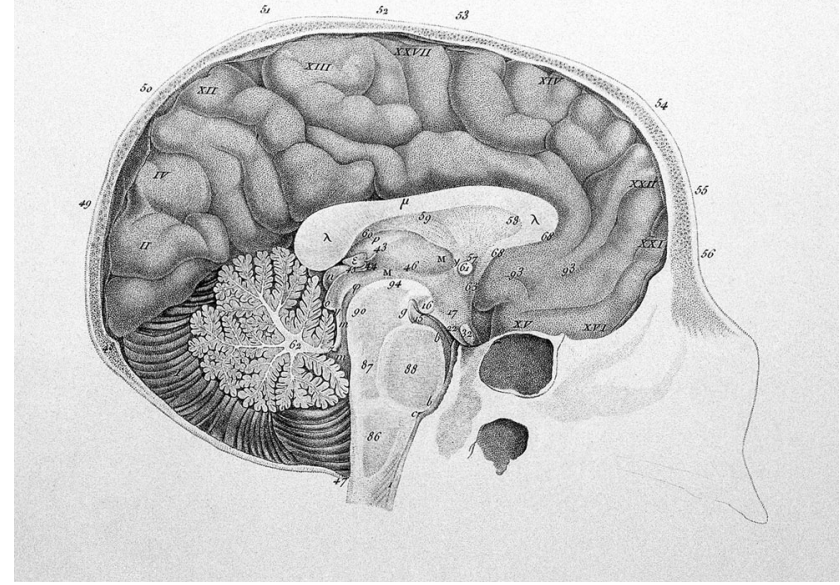

Fig. 2 Cover picture: Spurzheim's drawing of the medial surface of the brain. Notice the innovative denomination of the diencephalon structures [14]

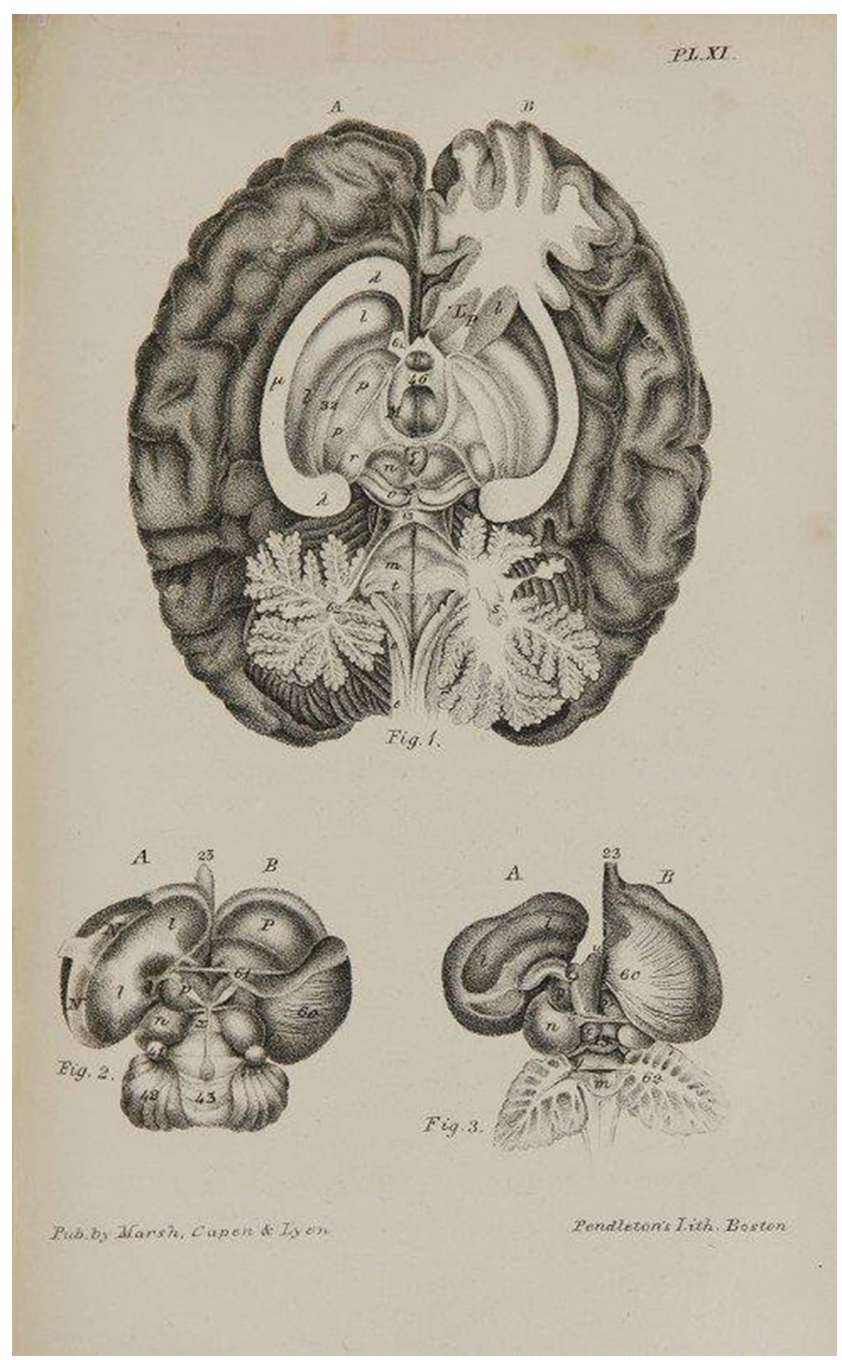

Fig. 3 Spurzheim's depiction of diencephalon external nuances and its relation with the telencephalon and mesencephalon [14] 


\section{Legacy and later life}

Spurzheim made significant contributions to our understanding of the anatomy and comparative anatomy of the brain [15]. However, the quackery related to phrenology itself would overshadow the observations that Spurzheim made on human brain anatomy [16]. Interestingly, he was also interested in patients with myelomeningocele and tried to determine the connection between hydrocephalus and the myelomeningocele by blowing air into the cut spinal cord in the neck to see if this would distend the distal lumbar sac. Wishing to further spread his knowledge, Spurzheim traveled to the USA in 1832. Fleeing cholera outbreaks in New York, he traveled to New Haven and them to Boston. In Boston, he delivered a course on anatomy of the brain for physicians, and two popular courses of phrenology, aimed at the general population. In 1832, he became ill probably with typhoid fever and died at the age of 56 on November 17 of this year [17].

\section{Conclusions}

Spurzheim made many important observations about human brain anatomy. These contributions to our current understanding of neuroanatomy are often overshadowed by his participation in the pseudoscience of phrenology, but should be appreciated nonetheless.

\section{Compliance with ethical standards}

Conflict of interest The authors declare that there is no conflict of interest regarding the publication of this paper.

\section{References}

1. Walsh AA (1972) The American tour of Dr. Spurzheim. J Hist Med Allied Sci 27:187-205

2. Langoussis JEA (2013) Talking heads. https://collections. countway.harvard.edu/onview/exhibits/show/talking-heads. Accessed 22 Jun 2016

3. Walsh AA (1976) Phrenology and the Boston medical community in the 1830s. Bull Hist Med 50:261-273

4. Fischer W (1984) [Franz Joseph Gall and Johann Kaspar Spurzheim - forerunners of biological psychiatry]. Psychiatr Neurol Med Psychol 36:433-437

5. Zola-Morgan S (1995) Localization of brain function: the legacy of Franz Joseph Gall (1758-1828). Annu Rev Neurosci 18: 359-383

6. Schatzki SC (1998) Johann Caspar Spurzheim. AJR Am J Roentgenol 171:1296

7. Finger S (2000) Minds behind the brain: a history of the pioneers and their discoveries. Oxford University Press

8. Boshears R, Whitaker H (2013) Phrenology and physiognomy in Victorian literature. Prog Brain Res 205:87-112

9. Spurzheim JC, Gall FJ (1815) The physiognomical system of Drs. Gall and Spurzheim

10. Spurzheim J (1884) Outlines of phrenology. Marsh, Capen \& Lyon

11. Follen C (1832) Funeral oration delivered before the citizens of Boston assembled at the old south church, November XVII at the burial of Gaspar Spurzheim. Marsh, Capen \& Lyon, Boston, pp. 1-28

12. Spurzheim JG, Brigham A (1836) Observations on the deranged manifestations of the mind, or insanity. Marsh, Capen \& Lyon

13. Spurzheim JG (1828) A View of the Elementary Principles of Education: founded on the Study of the Nature of Man. Treuttel, Würtz and Richter

14. Spurzheim JG (1826) The anatomy of the brain: with a general view of the nervous system. S. Highley

15. Slack DB (1844) Theory of Gall and Spurzheim. The Boston Medical and Surgical Journal (1828-1851). American Periodicals Series II, Boston, p 5

16. Filley CM (2010) Chapter 35: the frontal lobes. Handb Clin Neurol 95:557-570

17. Kleinman LC, McHenry LC Jr (1984) Fragments of neurologic history: phrenology's founders look at the spinal cord. Neurology 34:505

18. 1844) Theory of Gall and Spurzheim. Boston Med Surg J 30:9-13 